\title{
Uzaktan Eğitim Öğrencilerinin Çevrim İçi Teknolojilere Yönelik Öz Yeterlik Algılarının İncelenmesi ${ }^{a}$
}

\author{
Esma YILDIZ ${ }^{\mathrm{b}, \mathrm{c}}$, Süleyman Sadi SEFEROĞLUd
}

\section{Özet}

$\mathrm{Bu}$ çalışmanın amacı uzaktan eğitim öğrencilerinin çevrim içi teknolojilere yönelik öz yeterlik algılarının çeşitli değişkenler açısından incelenmesidir. Çalışmada nicel araştırma yöntemlerinden betimsel araştırma yöntemi kullanılmıştır. Katılımcılar bir uzaktan eğitim uygulama ve araştırma merkezinde (UZEM) 5 farklı ön lisans programına kayıtlı 175 öğrenciden oluşmaktadır. Araştırmada iki adet veri toplama aracı kullanılmıştır. İlk veri toplama aracı demografik bilgilerin toplandığı kişisel bilgi formudur. İkinci veri toplama aracı Çevrim İçi Teknolojilere Yönelik Öz Yeterlik Algısı Ölçeği'dir. Çalışmada elde edilen bulgular uzaktan eğitim öğrencilerinin çevrim içi teknolojilere yönelik öz yeterlik algılarının yüksek olduğu göstermektedir. Ek olarak uzaktan eğitim öğrencilerinin çevrim içi teknolojilere yönelik öz yeterliklerinin cinsiyet, bölüm ve yaş değişkenlerine göre farklılık gösterdiği anlaşılmıştır. Bu doğrultuda uzaktan eğitim öğrencilerinin çevrim içi teknolojilere yönelik öz yeterliklerini etkileyen ne tür faktörler olduğuyla ilgili bir araştırma yapılması önerilmiştir.
Anahtar Kelimeler

Uzaktan Eğitim

Çevrim İçi Teknolojiler

Öz Yeterlik

Makale Hakkında

Geliş Tarihi: 18.01.2019

Kabul Tarihi: 13.03.2020

Doi: 10.18026/cbayarsos.514904

\section{Examination of Self-Efficacy Perception of Distance Education Students About Online Technologies}

\begin{abstract}
The purpose of this study is to examine distance students' self-efficacy perception about online technologies in terms of various variables. In this study, descriptive research method, a quantitative method, is used. Participants are 175 students from five different associate degree programs in distance learning application and research center. In the scope of this study, two data collection tools were used. The first data collection tool is a personal information form by which demographic data were collected. The second data collection tool is the online technologies self-efficacy scale. According the obtained findings, distance education students have high self-efficacy about online technologies. In addition, the findings showed that distance education students' self-efficacy about online technologies varies according to gender, department, and age. Thus, it is recommended to investiagate the factors affecting distance education students' self-efficacy for online technologies.
\end{abstract}

Keywords

Distance Education

Online Technologies

Self-Efficacy

About Article

Received: 18.01.2019

Accepted: 13.03.2020

Doi: 10.18026/cbayarsos.514904

\footnotetext{
a Bu çalışmanın bir kısmı Uluslararası Bilim ve Eğitim Kongresi'nde (2018) sözlü bildiri olarak sunulmuştur.

b İletişim Yazarı: eesmayldz@gmail.com

c Arş. Gör, Amasya üniversitesi /Eğitim Fakültesi, Bilgisayar ve Öğretim Teknolojileri Eğitimi Bölümü, ORCID: 0000-0002-0916-9924

d Prof. Dr., Hacettepe Üniversitesi/ Eğitim Fakültesi, Bilgisayar ve Öğretim Teknolojileri Eğitimi Bölümü, ORCID: 0000-0002-5010-484X
} 


\section{Giriş}

Öz yeterlik bireyin öğrenmeyi gerçekleştirme ve davranışları geliştirme konusunda kendi kapasitesine olan inancıdır (Bandura, 1999; Gallagher, 2012; Zimmerman, 1995). Diğer bir deyişle öz yeterlik bireylerin becerilerini ve kapasitelerini değerlendirip bunları davranışa dönüştürmesi (Schunk, 2009) ve bir hedefe ulaşmada başarılı olma kabiliyetine inanmasıdır.

Öz yeterlik, kişinin fiziksel veya psikolojik özellikleri gibi kişisel niteliklerden ziyade faaliyetleri yerine getirme yeteneklerinin değerlendirilmesini içerir (Zimmerman, 1995). Ek olarak öz yeterlik, insanların gerektiğinde davranışları yürütebileceklerine inanıp inanmadığını değerlendirmeleridir (Gallagher, 2012). Bu bağlamda öğrenciler verilen görevin gerektirdiklerini yerine getirme konusunda kendilerini yargilarlar.

Öz yeterlik algıları öğrencilerin öğrenme motivasyonlarının üzerinde bir etkiye sahiptir. Zayıf bir öz yeterlik algısına sahip öğrenciler öğrenmeye daha az isteklidir, öğretim görevlerine yeterince odaklanamazlar, zorluklarla yüzleşmek istemezler veya bu zorlukların üstesinden gelmek için yeterli çabayı göstermezler (Bandura, 1993). Öz yeterlik algısı yüksek olan öğrenciler, diğer öğrencilere göre zorluklarla karşılaştıklarında, sınıfta daha fazla ve daha uzun süre çalışmakta, daha az olumsuz duygusal tepkiler vermektedirler. Bu bağlamda yüksek öz yeterlik, öğrencileri belirli öğrenme stratejilerini kullanmaya motive edebilir. Kısaca öz yeterliğin öğrenme ve performansı etkileyen önemli bir bileşen (Schunk, 2009) olduğu söylenebilir.

Tek bir eğilim olarak görülmeyen öz yeterlik algısı, çok boyutlu olup, ilgili alan temelinde farklılık gösteren bir yapıya sahiptir (Zimmerman, 2000). İlgili alanlarda öz yeterliği değerlendirme süreci ise öğrenenlerin kişisel, davranışsal ve çevresel bileşenlerin katkılarını değerlendirdikleri bir süreçtir (Schunk, 2009). Öz yeterlik farklı durumlarda, birtakım değişkenlerden olumlu veya olumsuz yönde etkilenebilir. Temelde sosyal psikoloji alanında geliştirilmiş bir kavram olan öz yeterlik pek çok alanda ve farklı disiplinlerde ele alınan bir kavramdır (Akkoyunlu ve Orhan, 2003). Bu alanlardan biri de çevrim içi ortamlardır. Çevrim içi öğrenmede bilgisayar öz yeterliği önemli olsa da araştırmacılar genellikle çevrim içi öğrenmenin çok yönlü olması nedeniyle farklı alanlarda öz yeterlik gerektirdiğini ileri sürmektedirler. Öz yeterlik; çevrim içi öğrenme ortamlarında gerçekleştirilen uzaktan eğitimde, beklentilerin karşılanması sürecinde göz önünde bulundurulması gereken önemli bir değişkendir. Bu ortamlarda; öğreticiler öncelikle çevrim içi derslerinde öğrencilerin teknoloji kullanma becerilerini belirleyerek, eksiklerinin giderilmesi için birtakım önlemler alabilirler.

Horzum ve Çakır (2009) çevrim içi ortamlarda öz yeterliği; uzaktan öğrenmeye, ders içeriğine ve çevrim içi teknolojilere yönelik özeyeterlik algısı olmak üzere üç şekilde ele almışlardır. Buna ilave olarak Shen, Cho, Tsai ve Marra (2013) çalışmalarında açımlayıcı faktör analizi yoluyla, çevrim içi öğrenme öz yeterliğini beş boyut olarak belirlemişlerdir. Bunlar; (a) çevrim içi bir kursu tamamlamak için öz yeterlik, (b) sınıf arkadaşlarıyla sosyal olarak etkileşim kurabilmek için öz yeterlik, (c) bir kurs yönetim sistemindeki araçların ele alınması için öz yeterlik (d) çevrim içi bir kursta öğreticilerle etkileşimde bulunma öz yeterliği ve (e) akademik amaçlarla sınıf arkadaşlarıyla etkileşim kurmak için öz yeterlik şeklindedir. Bu çalışmada ise çevrim içi ortamlarda öz yeterlik; çevrim içi öğrenmeye (Nahm ve Resnick, 2008; Shen, Cho, Tsai ve Marra, 2013; Zhang, Li, Duan ve Wu, 2001), ders içeriğine (Lee ve Witta, 2001; Wang ve Newlin, 2002), çevrim içi iletişime (Demir ve Yurdugül, 2015) ve çevrim içi teknolojilere 
(Lee ve Witta, 2001; Miltiadou ve Yu, 2000; Puzziferro, 2008) yönelik öz yeterlik olmak üzere dört farklı şekilde ele alınmıştır.

Çevrim içi öğrenme ortamları var olan öğrenme imkânlarının en dinamik ve zenginleştirici biçimlerinden biridir (Miltiadou ve Yu, 2000). Schunk'ın (2012) öğrenme tanımından yola çıkıldığında; çevrim içi öğrenme öz yeterliği, öğrenenlerin uzaktan öğrenme ortamlarında bilgi, beceri, strateji, inanç, tutum ve davranışların edinimini ve değiştirilmesini gerçekleştirmeye yönelik öz yeterlik algısı olarak tanımlanabilir. Çevrim içi öğrenmede bilgisayarları ve Web'i bilmeyen öğrenenler, genellikle bunları kullanmaya ilişkin becerilerine daha az güvenirler (Nahm ve Resnick, 2008).

Çevrim içi öğrenme ortamları, öğrencilerin ve öğretmenlerin birbirleriyle iletişim kurup çevrim içi teknolojiler yoluyla ders içerikleriyle etkileşimde bulunduğu ortamlardır (Bolliger ve Wasilik, 2009; Miltiadou ve Yu, 2000; Pearson ve Trinidad; 2005). Bu ortamlarda öğreticiler diğer katılımcılarla ve öğretmenle gerek eşzamanlı gerekse eşzamanlı olmayan çevrim içi iletişim araçlarını kullanarak etkileşim kurmaktadırlar (Wang, 2008). Ancak bu süreçte birçok öğrenci çevrim içi teknolojileri kullanmada çeşitli güçlüklerle karşılaşmaktadır (Altıparmak, Kurt ve Kapıdere, 2011; Miltiadou ve Yu, 2000). Bu güçlüklere örnek olarak, uzaktan eğitime yeni başlayan öğrencilerin öğrenme yönetim sistemini (ÖYS) takip konusunda yaşadıkları zorluklar ve bilgisayar ile interneti kullanmada endişeli olmaları ve bu eğilimin performanslarına yansıması gösterilebilir. Çalışma konusunda öz disipline, bilgi ve teknolojik alt yapıya sahip olmamaları halinde bu öğrencilerin başarısız olması muhtemeldir (Altıparmak, Kurt ve Kapıdere, 2011). Bu öğrenciler bunun yanı sıra öğrenme ortamındaki diğer katılımcılar ve öğretim elemanıyla iletişim kurmada, içeriklere nasıl erişeceklerini anlamada daha fazla zaman harcama eğilimindedirler (Miltiadou ve Yu, 2000).

Çevrim içi iletişim öz yeterliği, bireylerin çevrim içi bir ortamın kendine özgü dil ve kültürünü ne kadar çok anladıklarına ve bu ortamlarda kendilerini ne kadar iyi ifade edebildiklerine ilişkin olarak inançları şeklinde tanımlanabilir (Demir ve Yurdugül, 2015). Çevrim içi ortamlarda karşılaşılan bir diğer öz yeterlik algısı çevrim içi bir ders içeriğine yönelik öz yeterlik algısıdır. Öğrenenin derse karşı motivasyonunda ve ilgili derste başarılı olmasında öğrenme içeriğine yönelik yüksek öz yeterliğe sahip olması önemlidir (Lee ve Witta, 2001). Fakat ders içeriği ile ilgili olarak sahip olunan öz yeterliğin yeterli derecede olması o yeterliğe sahip bireyin bir çevrim içi derste başarılı olabilmesi için yeterli olmayabilir (Horzum ve Çakır, 2009). Çünkü çevrim içi derslerde başarılı olmak için çevrim içi teknolojilerin yaygın şekilde kullanılması önemlidir (Lee ve Witta, 2001).

Öte yandan çevrim içi teknolojilere yönelik öz yeterlik ise ders materyallerine erişmede, eposta gönderip almada, İnternet'te gezinme ve bilgi bulma için arama yapmada teknolojileri iyi kullanabilmekle ilgilidir (Lee ve Witta, 2001). Çevrim içi derslerde öğrencilerin başarılı olabilmeleri ve katılımlarının sağlanması için çevrim içi teknolojilere yönelik öz yeterlik algıları önemli bir faktördür (Horzum ve Çakır, 2009). Bu ortamlarda kişinin internet, bilgisayar ve diğer ilgili bilgi ve iletişim teknolojilerini (BİT) kullanmada ne kadar iyi olduğuna yönelik bir inancı vardır (Demir ve Yurdugül, 2015). Çevrim içi öğrenme ortamları internet ağları üzerinden sağlandığından, kişilerin teknolojiyi kullanmaya yönelik öz yeterliği ile ilgili değerlendirmelerin yapılması özellikle önemlidir (Hung, Chou, Chen ve Own, 2010). Uzaktan eğitimde yüksek öz yeterlik seviyelerine sahip olan katılımcıların daha üretken oldukları ve memnuniyet düzeylerinin yüksek olduğu bilinmektedir. Bu bağlamda bu kişiler 
uzaktan çalışırken herhangi bir sorunla karşılaştıklarında durumla daha iyi baş edebilirler (Eastin ve LaRose, 2000).

Çevrim içi öğrenmeye yönelik öz yeterlik algısı ile ilgili yapılan araştırmalarda incelenen değişkenler; öz düzenleme, motivasyon, başarı, internet kullanım deneyimi ve memnuniyet şeklindedir (Öztürk ve Kert, 2017; Wang, Shannon ve Ross, 2013). Bu çalışma; katılımcıların bireysel özeliklerinin dikkate alınması ve tamamının uzaktan eğitim öğrencisi olması yönüyle önemlidir. Uzaktan eğitim öğrencilerinin çevrim içi teknolojilere yönelik öz yeterlik algılarının farklı değişkenler doğrultusunda ele alınması, öz yeterlik algılarının yükseltilebilmesi konusunda bir bakış açısı kazandırabilir. Öğrenenlerin çevrim içi teknolojileri kullanma konusunda kendilerine yönelik öz yeterliklerinin düşük olmasının, çevrim içi teknolojileri kullanmada yaşanan çeşitli güçlüklerin nedenlerinden olduğu düşünülmektedir. $\mathrm{Bu}$ durumdaki öğrencilerin ilgili teknolojileri kullanma konusunda yeterli düzeyde bir öz yeterliğe sahip olmaları başarısızlık durumunun önüne geçmede yardımcı olabilir.

Uzaktan eğitim öğrencilerin çevrim içi teknolojilerle öz yeterlik algılarını belirlenmesi, çevrim içi ortamları düzenlerken bu öğrenciler için iyileştirmeler yapmada katkı sağlayabilir. Bu nedenle öğreticilerin de çevrim içi derslere başlamadan önce öğrencilerin teknoloji kullanma beceri düzeylerini belirlemeleri ve böylece gözlenen olası eksikliklerin giderilmesi gerekir (Miltiadou ve Savenye, 2003; Miltiadou ve Yu, 2000).

\section{Araştırmanın Amacı}

$\mathrm{Bu}$ çalışmada uzaktan eğitim öğrencilerinin çevrim içi teknolojilere yönelik öz yeterlik algılarının incelenmesi amaçlanmıştır. Bu amaca ulaşma sürecinde aşağıdaki sorulara yanıt aranmıştır:

1. Uzaktan eğitim öğrencilerinin çevrim içi teknolojilere yönelik öz yeterlik algısı ne düzeydedir?

2. Uzaktan eğitim öğrencilerinin çevrim içi teknolojilere yönelik öz yeterlik algıları cinsiyete göre farklılaşmakta mıdır?

3. Uzaktan eğitim öğrencilerinin çevrim içi teknolojilere yönelik öz yeterlik algıları okudukları bölüme göre farklılaşmakta mıdır?

4. Uzaktan eğitim öğrencilerinin çevrim içi teknolojilere yönelik öz yeterlik algıları yaş aralığına göre farklılaşmakta mıdır?

\section{Yöntem}

Uzaktan eğitim öğrencilerinin çevrim içi teknolojilere yönelik öz yeterlik algılarının incelendiği bu çalışmada, betimsel araştırma yöntemlerinden kesitsel tarama kullanılmıştır. Kesitsel tarama araştırmaları; belirli bir örneklemde, belirli bir zamanda, belirli bir konunun sıklığının veya düzeyinin saptandığı araştırmalardır (Fraenkel, Wallen ve Hyun, 2012). Bu çalışmada uzaktan eğitim öğrencilerinin cinsiyet, bölüm ve yaş aralığı değiş̧kenleri açısından çevrim içi teknolojilere yönelik öz yeterlik algıları saptanmaya çalışılmıştır. 


\section{Çalışma Grubu}

Araştırmanın çalışma grubunu bir üniversitenin Uzaktan Eğitim Uygulama ve Araştırma Merkezi'nde (UZEM) beş ön lisans programına kayıtlı öğrenciler oluşturmaktadır. Çalışma grubu oluşturulurken UZEM'deki beş ön lisans programının 798 öğrencisine e-posta yoluyla ulaşılmış ve araştırmaya katkı sağlamak için gönüllü olan öğrencilerin ölçeği doldurmaları rica edilmiştir. Bu bölümler "Tıbbi Dokümantasyon ve Sekreterlik, Çocuk Gelişimi, İnternet ve A $\breve{g}$ Teknolojileri, Mekatronik ve Elektrik" bölümleridir. İlgili e-postaya dönüş yapan 175 katılımcı bu araştırmanın çalışma grubunu oluşturmaktadır. Katılımcıların demografik bilgileriyle ilgili dağılımlar Tablo 1'de sunulmaktadır.

Tablo 1. Çalışma Grubunun Demografik Bilgilerinin Dağılımı

\begin{tabular}{lccc}
\hline Cinsiyet & Yaş Aralığı & f & \% \\
\hline \multirow{3}{*}{ Kadın } & $16-25$ & 88 & 73.9 \\
& $26-35$ & 24 & 20.2 \\
& $36-45$ & 7 & 5.9 \\
& Toplam & 119 & 100,0 \\
\hline \multirow{3}{*}{ Erkek } & $16-25$ & 29 & 51.8 \\
& $26-35$ & 19 & 33.9 \\
& $36-45$ & 8 & 14.3 \\
& Toplam & 56 & 100,0 \\
\hline
\end{tabular}

Cinsiyet ve yaş aralığına ilişkin dağılımların sunulduğu Tablo 1'deki verilere göre katılımcılar 119 kadın ve 56 erkekten oluşmaktadır. Toplam 175 katılımcının bölümlere dağılımları Tıbbi Dokümantasyon ve Sekreterlik bölümünde 51 katılımcı, Çocuk Gelişimi bölümünde 78 katılımcı, İnternet ve Ağ teknolojileri bölümünde 12 katılımcı, Mekatronik bölümünde 16 katılımcı, Elektrik bölümünde 18 katılımcı şeklindedir. Bu katılımcılar ilgili eğitim-öğretim yılını tamamlamış öğrencilerden oluşmaktadır.

\section{Veri Toplama Araçları}

$\mathrm{Bu}$ araştırmada veri toplama sürecinde iki araç kullanılmıştır. Araçların ilki katılımcıların demografik bilgilerinin toplanmasının amaçlandığı kişisel bilgi formudur. Çalışmada kullanılan ikinci veri toplama aracı, Miltiadou ve Yu (2000) tarafından geliştirilen ve Horzum ve Çakır (2009) tarafından Türkçe'ye uyarlanan Çeorimiç̧i Teknolojilere Yönelik Öz yeterlik Algısı Ölçeği'dir. Bu ölçeğin geçerlik-güvenirlik çalışmaları çevrim içi ortamda ders deneyimi olan 276 katılımcıdan toplanan verilerle gerçekleştirilmiştir. Ölçeğin yapılan açımlayıcı faktör analizi ve doğrulayıcı faktör analizleri sonucunda dört faktörlü yapıya sahip olduğu görülmüştür (Bkz. Şekil 1). 


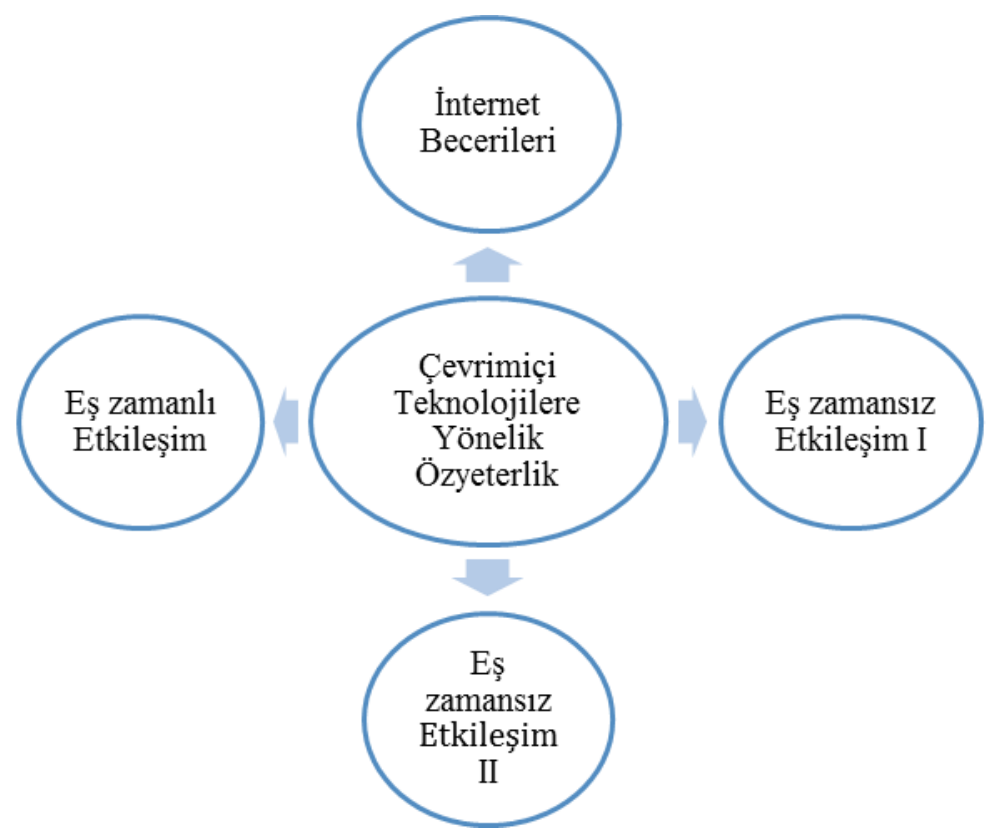

Şekil 1. Çevrim içi teknolojilere yönelik öz yeterlik algısı ölçeğinin faktörleri

Ölçekteki ilk faktör olan "İnternet Becerileri” dokuz maddeden, ikinci faktör olan "Eş zamanlı Etkileşim" dört maddeden, üçüncü faktör olan "Eş zamansız Etkileşim I" dokuz maddeden, dördüncü faktör olan "Eş zamansız Etkileşim II" ise yedi maddeden oluşmaktadır. Horzum ve Çakır (2009) tarafından yapılan Çevrim İçi Teknolojilere Yönelik Öz yeterlik Algısı Ölçeği'nin güvenirlik analiz sonuçları Tablo 2'deki gibidir.

Tablo 2. Çevrim İçi Teknolojilere Yönelik Öz Yeterlik Algısı Ölçeği Faktörlerinin Güvenirlik Değerleri

\begin{tabular}{lc}
\hline Faktörler & Cronbach Alfa \\
\hline İnternet Becerileri & .89 \\
Eş zamanlı Etkileşim & .85 \\
Eş zamansız Etkileşim I & .90 \\
Eş zamansız Etkileşim II & .86 \\
\hline
\end{tabular}

Ölçeğin güvenirliği için bakılan Cronbach Alpha iç tutarlık kat sayısı 0.94 olarak bulunmuştur. Tablo 2' den anlaşılacağ1 üzere ölçek alt faktörlerinin güvenirlik değerleri, İnternet Becerileri faktörü için 0.89, Eş zamanlı Etkileşim faktörü için 0.85, Eş zamansız Etkileşim I faktörü için 0.90 ve Eş zamansız Etkileşim II faktörü için $0.86^{\prime}$ dır.

İnternet Becerileri faktörü internet kullanımıyla ilgilidir. Eş zamanlı Etkileşim faktörü eşzamanlı sohbet araçlarını kullanarak etkileşime girmekle ilgilidir. Eş zamansız Etkileşim I faktörü eş zamansız e-posta araçlarını kullanarak etkileşime girmekle ilgiliyken son faktör olan Eş zamansız Etkileşim II eş zamansız haber grubu ve forum gibi araçları kullanarak etkileşime geçmekle ilgilidir. 
Çalışmada ölçeğin güvenirliği için bakılan Cronbach Alpha iç tutarlık kat sayısı İnternet Becerileri faktörü için 0.88, Eş zamanlı Etkileşim faktörü için 0.82, Eş zamansız Etkileşim I faktörü için 0.92, Eş zamansız Etkileşim II faktörü için 0.93 olarak bulunmuştur. Bu değerler Horzum ve Çakır (2009) tarafından elde edilen ve Tablo 2'de sunulan analiz sonuçlarıyla benzerlik göstermektedir.

\section{Verilerin Analizi}

$\mathrm{Bu}$ çalışmanın verileri bir bilgisayar programı ile analiz edilmiştir. İstatistiksel olarak veriler tanımlayıcı ve çıkarımsal istatistik kapsamında ele alınmıştır. Bu çerçevede, öncelikle demografik soruların frekans dağılımları ele alınmıştır. Verilerin analizinde, çok sayıdaki gözlemi özetlemek ve düzenlemek için betimsel istatistikler kullanılmıştır. Verilerin güvenilirliği ise Cronbach Alpha ile test edilmiştir. Daha sonra çalışmanın araştırma sorularına ilişkin bulgular incelenmiştir. Bu amaçla uzaktan eğitim öğrencilerinin çevrim içi teknolojilere yönelik öz yeterlik alg1 puanlarının; cinsiyete göre değişip değişmediğinin incelenmesi amacıyla bağımsız örneklemler $\mathrm{t}$ testi, bölümlerine ve yaşlarına göre değişip değişmediğinin incelenmesi amacıyla Kruskal-Wallis h testinden yararlanılmıştır. İlgili testler kullanılmadan önce sayıltıları test edilmiştir. Yapılan Kruskal-Wallis h testi sonucunda anlamlı fark bulunduğu durumlarda, bu anlamlı farkın hangi gruplar arasında olduğunu belirlemek amacıyla Man Whitney u testi kullanılmıştır.

\section{Bulgular}

Bulgular bu araştırmanın amacı doğrultusunda belirlenen alt problemler ayrı ayrı cevaplandırılacak şekilde sunulmuştur. Ayrıca araştırma sorularına ilişkin elde edilen bulgular alan yazında var olan çalışmalarla ilişkilendirilerek tartışılmıştır.

\section{Uzaktan Ĕ̆itim Öğrencilerinin Çevrim içi Teknolojilere Yönelik Öz yeterlik Algı Durumları}

$\mathrm{Bu}$ çalışmanın ilk araştırma sorusu “Uzaktan eğitim öğrencilerinin çevrim içi teknolojilere yönelik öz yeterlik algıları ne düzeydedir?" şeklinde belirlenmiştir. Bu soruya yanıt bulmak için 175 katılımcının Çevrim İçi Teknolojilere Yönelik Öz yeterlik Algısı Ölçeği'ne verdikleri cevaplar betimsel olarak incelenmiştir. Bu soruya ilişkin analiz sonuçları Tablo 3'te sunulmuştur.

Tablo 3. Uzaktan Eğitim Öğrencilerinin Çevrim içi Teknolojilere Yönelik Öz yeterlik Algılarıyla İlgili Ortalama ve Standart Sapma Değerlerinin Dağılımı

\begin{tabular}{lcc}
\hline Faktörler & $\overline{\mathbf{X}}$ & Ss \\
\hline İnternet Becerileri & 4.54 & 0.55 \\
Eş zamanlı Etkileşim & 4.33 & 0.73 \\
Eş zamansız Etkileşim I & 4.47 & 0.67 \\
Eşzzamansız Etkileşim II & 4.11 & 0.89 \\
Ölçek geneli & $\mathbf{4 . 3 9}$ & $\mathbf{0 . 6 0}$ \\
\hline
\end{tabular}

$N=175$ 
Uzaktan eğitim öğrencilerinin çevrim içi teknolojilere yönelik öz yeterlik algılarını tespit etmek amacıyla kullanılan 29 maddelik ölçeğin betimsel bulguları her bir faktör için ayrı ayrı incelenmiştir. Tablo 4 'te görüldüğü üzere öz yeterlik algısı puanının $\overline{\mathbf{X}}$ (aritmetik ortalama) değeri 4.39, standart sapması 0.60' dır. Ölçek faktörlerine bakıldığında, İnternet Becerileri ve Eş zamansız Etkileşim I faktörlerinin ortalamalarının diğer faktörlere göre daha yüksek olduğu görülmektedir. Veriler genel olarak incelendiğinde ise uzaktan eğitim öğrencilerinin çevrim içi teknolojilere yönelik öz yeterlik algılarının yüksek olduğu anlaşılmaktadır.

Uzaktan Eğitim Öğrencilerinin Çevrim içi Teknolojilere Yönelik Öz yeterlik Alg̨larının Cinsiyet Açısından Farklılaşma Durumları

Bu çalışmanın ikinci sorusu “Uzaktan eğitim öğrencilerinin çevrim içi teknolojilere yönelik öz yeterlik algıları cinsiyete göre farklılaşmakta mıdır?" şeklinde belirlenmiştir. Bu soruda iki farklı örneklem grubunun ortalamalarını kıyaslayıp aralarında anlamlı bir fark olup olmadığını test etmek için bağımsız örneklemler için t-testi kullanılır. Bu iki örneklem kadın öğrenciler ve erkek öğrenciler şeklindedir. Bağımsız örneklemler için t-testine başlamadan önce varsayımların denenmesi gerekmektedir. Bu nedenle öğrencilerin öz yeterlik puanlarının normal dağılıp dağılmadığına bakılmıştır. Sonuç olarak öğrencilerin öz yeterlik puanlarının normal dağıldığ 1 ve varyansların homojen olduğu görülmüştür.

Tablo 4. Uzaktan Eğitim Öğrencilerinin Çevrim içi Teknolojilere Yönelik Öz yeterlik Alg1 Puanlarının Cinsiyete Göre Farklılaşma Durumlarıyla İlgili Verilerin Dağılımı

\begin{tabular}{lccccccc}
\hline Gruplar & $\mathbf{N}$ & $\overline{\mathbf{X}}$ & $\mathbf{s}$ & $\mathbf{t}$ & $\mathbf{P}$ & $\mathbf{s d}$ & $\mathbf{d}$ \\
\hline Kadın & 119 & 4.25 & 0.62 & -4.575 & 0.00 & 173 & 0.74 \\
\hline Erkek & 56 & 4.67 & 0.43 & & & & \\
\hline
\end{tabular}

Uzaktan eğitim öğrencilerinin öz yeterlik alg1 puanlarının cinsiyete göre değişip değişmediğinin incelenmesi amacıyla yapılan bağımsız örneklemler için $t$ testi sonucunda, kadınları ortalamasının ( $\overline{\mathbf{X}}=4.25)$, erkeklerin ortalamasından $(\overline{\mathbf{X}}=4.67)$ anlamlı olarak farklılık gösterdiği anlaşılmıştır ( $\mathrm{t}$ 0.05/2, 173 = -4.575, $\mathrm{p}<0.05)$. Bu durum erkek öğrencilerin çevrim içi teknolojilere yönelik öz yeterlik algılarının daha yüksek olduğunu göstermiştir. Hesaplanan etki büyüklüğü $(\mathrm{d}=0.74)$ farkın orta düzeyde olduğunu göstermektedir.

Uzaktan Ĕ̆itim Öğrencilerinin Çevrim içi Teknolojilere Yönelik Öz yeterlik Algılarının Okudukları Bölüm Açısından Farklılaşma Durumları

$\mathrm{Bu}$ çalışmanın üçüncü sorusu "Uzaktan eğitim öğrencilerinin çevrim içi teknolojilere yönelik öz yeterlik algıları okudukları bölüme göre farklılaşmakta mıdır?" şeklinde belirlenmiştir. Bu soruya yanıt bulmak üzere kullanılacak analize karar vermede öncelikle verilerin normal dağılımına bakılmıştır. Veriler normal dağılmadığı için parametrik testin varsayımlarını karşılamamıştır. Verilerin normal dağılmama nedeninin bölümlerde yer alan kişi sayısının farklılık göstermesinden olduğu düşünülmektedir. Verilerin normal dağılmaması üzerine; bağımsız ikiden fazla grup ortalaması arasındaki farkın test edilmesinde Kruskal-Wallis $\mathrm{H}$ testi kullanılmıştır. 
Tablo 5. Uzaktan Eğitim Öğrencilerinin Öz yeterlik Alg1 Puanlarının Bölümlerine Göre Karşılaştırılmasında Kruskal-Wallis H Testi Sonuçlarının Dağılımı

\begin{tabular}{lccccc}
\hline Bölümler & Sıra Ortalamaları & $\mathbf{x}^{\mathbf{2}}$ & $\mathbf{s d}$ & $\mathbf{p}$ & Anlamlı Fark \\
\hline $\begin{array}{l}\text { (1) Tıbbi Dokümantasyon ve } \\
\text { Sekreterlik }\end{array}$ & 75.94 & 25.471 & 4 & 0.000 & $1-5$ \\
& & & & $1-3$ \\
(2) Çocuk Gelişimi & & & $2-3$ \\
& 77.12 & & $2-4$ \\
(3) İnternet ve Ağ Teknolojileri & 127.25 & & $2-5$ \\
(4) Mekatronik & 113.06 & & \\
(5) Elektrik & 120.86 & & \\
\hline
\end{tabular}

Uzaktan eğitim öğrencilerinin öz yeterlik algı puanlarının bölümlere göre değişip değişmediğini test etmek amacıyla yapılan Kruskal-Wallis testi sonucunda anlamlı fark bulunmuştur $\left(\mathrm{x}^{2}(2)=25.471, \mathrm{p}<0.05\right)$. Bu anlamlı farkın hangi gruplar arasında olduğunu belirlemek için yapılan Man Whitney U testi sonucunda farkın; “Tıbbi Dokümantasyon ve Sekreterlik - İnternet ve A $\breve{g}$ teknolojileri", "Tibbi Dokümantasyon ve Sekreterlik Mekatronik”, “Tıbbi Dokümantasyon ve Sekreterlik - Elektrik” ve “Çocuk Gelişimi - İnternet ve Ağ teknolojileri”, "Çocuk Gelişimi - Mekatronik", "Çocuk Gelişimi - Elektrik" bölümleri arasında olduğu belirlenmiştir.

Uzaktan Ĕ̆itim Öğrencilerinin Çevrim içi Teknolojilere Yönelik Öz yeterlik Algılarının Yaş Aralıklarına Göre Farklılaşma Durumları

$\mathrm{Bu}$ çalışmanın dördüncü sorusu "Uzaktan eğitim öğrencilerinin çevrim içi teknolojilere yönelik öz yeterlik algıları yaş aralıklarına göre farklılaşmakta mıdır?" şeklinde belirlenmiştir. $\mathrm{Bu}$ soruyla ilgili veriler normal dağılmadığı için parametrik testin varsayımlarını karşılamamıştır. Bu nedenle bağımsız ikiden fazla grup ortalaması arasındaki farkın test edilmesinde Kruskal-Wallis H testi kullanılmıştır.

Tablo 6. Uzaktan Eğitim Öğrencilerinin Öz yeterlik Alg1 Puanlarının Yaş Aralıklarına Göre Karşılaştırılmasında Kruskal-Wallis H Testi Sonuçlarının Dağılımı

\begin{tabular}{llcccc}
\hline Yaş Aralığı & Sıra ortalamaları & $\mathbf{x}^{2}$ & sd & $\mathbf{p}$ & Anlamlı fark \\
\hline (1) $16-25$ & 82.23 & 10.132 & 2 & 0.006 & $1-3$ \\
(2) $26-35$ & 90.48 & & & & $2-3$ \\
(3) 36 ve üstü & 125.90 & & & & \\
\hline
\end{tabular}

Uzaktan eğitim öğrencilerinin öz yeterlik algı puanlarının yaş aralıklarına göre değişip değişmediğini test etmek amacıyla yapılan Kruskal-Wallis $\mathrm{h}$ testi sonucunda anlamlı fark 
bulunmuştur $\left(\mathrm{x}^{2}{ }_{(2)}=10.132, \mathrm{p}<0.05\right)$. Bu anlamlı farkın hangi gruplar arasında olduğunu belirlemek için yapılan Man Whitney U testi sonucunda farkın; yaşı 16-25 aralığında olan ile yaşı 36 ve üstü aralığında olan, yaşı 26-35 aralığında olan ile yaşı 36 ve üstü aralığında olan katılımcılar arasında olduğu belirlenmiştir.

\section{Tartışma}

$\mathrm{Bu}$ bölümde, araştırma problemleri doğrultusunda yapılan analizler yoluyla elde edilen bulgular bağımsız değişkenler açısından ayrı ayrı ele alınıp yorumlanmıştır.

Uzaktan eğitimde öğrencilerin çevrim içi teknolojilere yönelik bilgi ve becerilere sahip olmalarının yanı sıra bu bilgi ve becerileri kullanma konusundaki öz yeterlik algılarının yüksek olması önemlidir (Akkoyunlu ve Kurbanoğlu, 2003). Araştırma kapsamında ilk olarak uzaktan eğitim öğrencilerinin çevrim içi teknolojilere yönelik öz yeterlik algıları ele alınmış ve bu öğrencilerin çevrim içi teknolojilere yönelik öz yeterlik algılarının yüksek olduğu anlaşılmıştır. Yaygın olarak çevrim içi teknolojilerin kullanıldığı uzaktan eğitim hizmetlerinde; öğrencilerin çevrim içi teknolojilere yönelik öz yeterlik algılarının yüksek olması, karşılaşılması muhtemel pek çok sorun ve engeli aşmak için çaba göstermelerini sağlayabilir (Akkoyunlu ve Orhan, 2003).

Alan yazında öğrenme stratejilerinden performansa kadar olan farklılıklar ve benzerlikler hakkında cinsiyet tartışması üzerine araştırmaya ihtiyaç olduğu paylaşılmaktadır (Yükseltürk ve Bulut, 2009). Farklı uzaktan eğitim ön lisans programlarında okuyan öğrencilerle yapılan bu araştırmada, öğrencilerin çevrim içi teknolojilere yönelik öz yeterlik algılarının cinsiyete göre farklılaştığı bulunmuştur. Öz yeterlik algısının cinsiyete göre farklılaştığına yönelik farklı araştırmaların bulguları (Betz ve Hackett, 1981; Britner ve Pajares, 2006; Çetin ve Güngör, 2014; Morgil, Seçken ve Yücel, 2004; Pajares ve Johnson, 1996) bu çalışmayı desteklemektedir.

Bu çalışmada erkek katılımcıların çevrim içi teknolojileri kullanmada kadın katılımcılara oranla kendilerini daha yeterli buldukları görülmüştür. Öz yeterliği cinsiyet açısından ele alan farklı çalışmaların sonucuna göre erkek katılımcıların öz yeterlik algıları kadın katılımcılarınkinden daha yüksektir (Çetin ve Güngör, 2014; Kabaran, Altıntaş ve Kabaran, 2016; Pajares ve Johnson, 1996). Diğer taraftan öz yeterlik algısı konusunda erkekler ve kadınlar arasında fark bulunmadığına yönelik araştırmalar da mevcuttur (Akbaş ve Çelikkaleli, 2006; Altunçekiç, Yaman ve Koray, 2005; Yaman, Cansüngü ve Altunçekiç, 2004).

$\mathrm{Bu}$ çalışmada uzaktan eğitim öğrencilerinin öz yeterlik alg1 puanlarının bölümlerine göre de farklılaştığ1 görülmüştür. Bu farklılaşma incelendiğinde İnternet ve A $\breve{g}$ Teknolojileri, Mekatronik ve Elektrik bölümü öğrencilerinin öz yeterlik algılarının daha yüksek olduğu görülmüştür. Bu bölümlerin öğretim programları temelde teknoloji kullanımına dayalı konuları içermektedir. Bu bölümlerde içerikler sayesinde öğrencilerin teknoloji bilgilerinin arttığ düşünülmektedir. Bu durum, alan bilgisinin artmasının öz yeterliği arttırdığ 1 şeklinde yorumlanabilir. Nitekim alan yazında bilgisayarların karmaşık ve biraz zahmetli bir teknolojiyi temsil ettikleri ve başarıyla çalıştırılabilmeleri için önemli beceri ve eğitim gerektirdiği ifade edilmektedir (Eastin ve LaRose, 2000). Ayrıca farklı çalışmalarda öğrencinin ilgili alanda sınıf seviyesi artıkça bölüme ilişkin öz yeterlik algısının arttığı görülmüştür (Altunçekiç, Yaman ve Koray, 2005).

Öte yandan uzaktan eğitim öğrencilerinin çevrim içi teknolojilere yönelik öz yeterlik alg1 puanlarının, yaşı büyük olanlar lehine farklılaştı̆̆ı görülmüştür. Öz yeterlik algısının yaş 
aralığına göre farklılaştığına yönelik farklı araştırma bulguları (Çetin ve Güngör, 2014) bu yönüyle bu çalışmayı desteklemektedir. Ancak bu araştırmada mevcut çalışmanın aksine katılımcıların yaşlarının daha genç olmasının, teknoloji kullanımında kendilerini daha yeterli hissetmelerini sağladığ1 düşünülmektedir. Bireylerin öz yeterliğini etkileyen çeşitli faktörler olabilir. Bu faktörlerden birinin de deneyim olduğu bilinmektedir (Bandura, 1986, Betz ve Hackett, 1981). Kişilerin yaşları ilerledikçe becerilerin yavaş yavaş arttığı bu sayede öz yeterliklerinin de artabileceği söylenebilir. Bu konuda yapılan araştırmalarda olumlu ve öğretici deneyimlerin öz yeterliği artırdığı ileri sürülmektedir (Akkoyunlu ve Orhan, 2003).

\section{Sonuç ve Öneriler}

Araştırmada uzaktan eğitim öğrencilerinin çevrim içi teknolojilere yönelik öz yeterlik algılarının incelenmesi amaçlanmıştır. Bu amaçla bir üniversitenin Uzaktan Eğitim Uygulama ve Araştırma Merkezi'nde (UZEM) ön lisans öğrencilerinin çevrim içi teknolojilere yönelik öz yeterlik algıları, cinsiyet, yaş, bölüm gibi çeşitli değişkenler açısından incelenmiştir. Çalışmada Miltiadou ve Yu (2000) tarafından geliştirilen ve Horzum ile Çakır (2009) tarafından Türkçe uyarlaması yapılan Çevrim İçi Teknolojilere Yönelik Öz yeterlik Algısı Ölçeği kullanılmıştır.

$\mathrm{Bu}$ araştırma kapsamında ulaşılan ilk sonuç uzaktan eğitim öğrencilerinin çevrim içi teknolojilere yönelik öz yeterlik algılarının yüksek olduğu şeklindedir. İkinci olarak uzaktan eğitim ön lisans öğrencilerinin çevrim içi teknolojilere yönelik öz yeterlik algıları cinsiyete göre ele alınmış ve erkeklerin kadınlara göre daha yüksek öz yeterlik algısına sahip oldukları sonucuna ulaşılmıştır. Erkekler günlük hayatta kadınlara göre daha fazla bilgisayar ve diğer teknolojilerle etkileşim halinde olmaktadırlar (Çetin ve Güngör, 2014). Bu nedenle bu durumun çevrim içi teknolojilere yönelik öz yeterliği de artırdığı düşünülmektedir. Üçüncü olarak uzaktan eğitim ön lisans öğrencilerinin çevrim içi teknolojilere yönelik öz yeterlik algıları bölümlerine göre ele alınmış, bilgisayar ve teknoloji içerik altyapısına sahip bölümlerde öz yeterlik inancının daha yüksek olduğu sonucuna ulaşılmıştır. Bu durum, bölümlerde sunulan içerikler sayesinde öğrencilerin teknoloji bilgilerinin arttığı, bu sayede çevrim içi teknolojilere yönelik öz yeterliğin de arttığ şeklinde yorumlanmıştır. Son olarak uzaktan eğitim ön lisans öğrencilerinin çevrim içi teknolojilere yönelik öz yeterlik algıları yaş aralığına göre ele alınmış, yaş aralığı arttıkça öz yeterlik inancının da arttığı sonucuna ulaşılmıştır. Bu durum bireylerin yaşları ilerledikçe becerilerinin artabileceği, bu sayede öz yeterliklerinin de artabileceği şeklinde yorumlanmıştır.

Sonuç olarak uzaktan eğitim öğrencilerinin öz yeterlik algıları çeşitli değişkenlere göre farklılık göstermektedir. Bu farklılıklar öğrencilerin performansında çeşitli risklerin ortaya çıkmasına yol açabilir. Bu tür durumların önüne geçmek için öğrenme-öğretme süreci öncesinde, öğrencilerin öz yeterlik algılarının ölçülmesi önerilmektedir. Böylece süreç başlamadan birtakım önlemler alınabilir. Bu önlemler iletişim seçeneklerinin çoğaltılması, daha sade bir arayüze sahip ÖYS’lerin kullanılması şeklinde olabilir. Ayrıca, bu öğrencilerin öğrenme-öğretme sürecini başarılı bir şekilde tamamlamasına yardımcı olmak için onlara özgü öğretimsel faaliyetler tasarlanabilir. Bu faaliyetler tasarlanırken uzaktan eğitim öğrencilerinin çevrim içi teknolojilere yönelik öz yeterliklerini etkileyen değişkenlerin göz önünde bulundurulmasının önemli olduğu söylenebilir. Bu bağlamda gelecekteki araştırmalarda öğrencilerin çevrim içi teknolojilere yönelik öz yeterliklerini etkileyen faktörlerin incelenmesi önerilmektedir. Bu faktörlerin bilinmesinin, öğrencilerin öz yeterlik algılarının öğretimsel faaliyetlerle geliştirilmesi sürecine katkılar getirebileceği söylenebilir. 


\section{Kaynakça}

Akbaş, A. ve Çelikkaleli, Ö. (2006). Sınıf öğretmeni adaylarının fen öğretimi özyeterlik inançlarının cinsiyet, öğrenim türü ve üniversitelerine göre incelenmesi. Mersin Üniversitesi Ĕ̆itim Fakültesi Dergisi, 2(1), 98-110.

Akkoyunlu, B. ve Kurbanoğlu, S. (2003). Öğretmen adaylarının bilgi okuryazarlığı ve bilgisayar öz yeterlik algıları üzerine bir çalışma. Hacettepe Üniversitesi Ĕ̆itim Fakültesi Dergisi, 24, 1-10.

Akkoyunlu, B. ve Orhan, F. (2003). Bilgisayar ve Ögretim Teknolojileri Egitimi (BÖTE) bölümü ögrencilerinin bilgisayar kullanma öz yeterlik inancı ile demografik özellikleri arasındaki ilişki. The Turkish Online Journal of Educational Technology, 2(3), 86-93.

Altıparmak, M., Kurt, İ. D. ve Kapıdere, M. (2011). E-öğrenme ve uzaktan eğitimde açık kaynak kodlu öğrenme yönetim sistemleri. XI. Akademik Bilişim Kongresi.

Altunçekiç, A., Yaman, S. ve Koray, Ö. (2005). Öğretmen adaylarının öz-yeterlik inanç düzeyleri ve problem çözme becerileri üzerine bir araştırma (Kastamonu İli Örneği). Kastamonu Ĕ̆itim Dergisi, 13(1), 93-102.

Bandura, A. (1994). Self-efficacy. In V. S. Ramachaudran (Ed.), Encyclopedia of human behavior (Vol. 4, pp. 71-81). New York: Academic Press. (Reprinted in H. Friedman [Ed.], Encyclopedia of mental health. San Diego: Academic Press, 1998).

Bandura, A. (1999). Social cognitive theory: An agentic perspective. Asian Journal of Social Psychology, 2(1), 21-41.

Betz, N. E., \& Hackett, G. (1981). The relationship of career-related self-efficacy expectations to perceived career options in college women and men. Journal of counseling psychology, 28(5), 399-410.

Bolliger, D. U., \& Wasılık, O. (2009). Factors influencing faculty satisfaction with online teaching and learning in higher education. Distance Education, 30(1), 103-116.

Britner, S. L., \& Pajares, F. (2006). Sources of science self-efficacy beliefs of middle school students. Journal of Research in Science Teaching, 43(5), 485-499.

Çelen, F. K., Çelik, A. ve Seferoğlu, S. S. (2011). Yükseköğretimde çevrim-içi öğrenme: Sistemde yaşanan sorunlar ve çözüm önerileri. Journal of European Education, 1(1).

Çetin, O. ve Güngör, B. (2014). İlköğretim öğretmenlerinin bilgisayar öz-yeterlik inançları ve bilgisayar destekli öğretime yönelik tutumları. Ondokuz Mayıs Üniversitesi Eğitim Fakültesi Dergisi, 33(1), 55-78.

Eastin, M. S., \& LaRose, R. (2000). Internet self-efficacy and the psychology of the digital divide. Journal of Computer-Mediated Communication, 6(1).

Demir, Ö., \& Yurdugül, H. (2015). The examination of prospective teachers' information and communication technology usage and online communication self-efficacy levels in Turkey. Procedia-Social and Behavioral Sciences, 176, 371-377.

Fraenkel, J., Wallen, N., \& Hyun (2012). How to design and evaluate research in education. Mc-Graw Hill: Boston. 
Gallagher, M. W. (2012). Self-Efficacy. (ed.) In V. S. Ramachaudran, Encyclopedia of human behavior (Vol.2, pp. 314-320). San Diego: Academic Press.

Gangadharbatla, H. (2008). Facebook me: Collective self-esteem, need to belong, and internet self-efficacy as predictors of the iGeneration's attitudes toward social networking sites. Journal of Interactive Advertising, 8(2), 5-15.

Horzum, M. B. ve Çakır, Ö. (2009). Çevrim içi teknolojilere yönelik öz-yeterlik algısı ölçeği Türkçe formunun geçerlik ve güvenirlik çalışması. Kuram ve Uygulamada Ĕ̆gitim Bilimleri Dergisi, 9(3), 1327-1356.

Hsu, M. H., \& Chiu, C. M. (2004). Internet self-efficacy and electronic service acceptance. Decision Support Systems, 38(3), 369-381.

Joo, Y. J., Bong, M., \& Choi, H. J. (2000). Self-efficacy for self-regulated learning, academic selfefficacy, and Internet self-efficacy in Web-based instruction. Educational Technology Research and Development, 48(2), 5-17.

Kabaran, H., Altıntaş, S. ve Kabaran, G. G. (2016). Öğretmen adaylarının eğitsel internet kullanım öz-yeterlik inançları ile akademik öz-yeterlik inançları arasındaki ilişkinin incelenmesi. Ĕ̆itim Kuram ve Uygulama Araştırmaları Dergisi, 2(1), 01-11.

Miltiadou, M., \& Savenye, W. C. (2003). Applying social cognitive constructs of motivation to enhance student success in online distance education. AACE journal, 11(1), 78-95.

Miltiadou, M., \& Yu, C. H. (2000). Validation of the Online Technologies Self-Efficacy Scale (OTSES). ERIC.

Morgil, İ., Seçken, N. ve Yücel, A. S. (2004). Kimya öğretmen adaylarının öz-yeterlik inançlarının bazı değişkenler açısından incelenmesi. BAÜ Fen Bilimleri Ensitüsü Dergisi, $6(1), 62-72$.

Öztürk, P. ve Kert, S. B. (2017). Bir Çevrim içi Öğrenme Ortamının, Yetişkinlerin Çevrim içi Öz yeterlik Algısı ve Akademik Başarılarına Etkisi. Acta Infologica, 1(1), 39-54.

Pajares, F., \& Johnson, M. J. (1996). Self-efficacy beliefs and the writing performance of entering high school students. Psychology in the Schools, 33(2), 163-175.

Puzziferro, M. (2008). Online technologies self-efficacy and self-regulated learning as predictors of final grade and satisfaction in college-level online courses. American Journal of Distance Education, 22(2), 72-89.

Shen, D., Cho, M. H., Tsai, C. L., \& Marra, R. (2013). Unpacking online learning experiences: Online learning self-efficacy and learning satisfaction. The Internet and Higher Education, 19, 10-17.

Schunk, D. H. (2009). Öğrenme teorileri: Ĕ̆gitimsel bir bakışla. (çev.) Muzaffer Şahin, Ankara: Nobel Yayın Dağıtım.

Schunk, D. H. (2012). Learning theories an educational perspective, 6th edition. Boston: Pearson Education.

Tsai, M. J., \& Tsai, C. C. (2003). Information searching strategies in web-based science learning: The role of Internet self-efficacy. Innovations in education and Teaching International, 40(1), 43-50. 
Wang, S. K. (2008). The effects of a synchronous communication tool (yahoo messenger) on online learners' sense of community and their multimedia authoring skills. Journal of Interactive Online Learning, 7(1), 59-74.

Yaman, S., Cansüngü, Ö. ve Altunçekiç, A. (2004). Fen bilgisi öğretmen adaylarının öz-yeterlik inanç düzeylerini incelenmesi üzerine bir araştırma. Türk Eğitim Bilimleri Dergisi, 2(3), 355364.

Yukselturk, E., \& Bulut, S. (2009). Gender differences in self-regulated online learning environment. Educational Technology \& Society, 12(3), 12-22. 